\title{
MÉTODO DE ARMAZENAMENTO DE SEMENTES DE GOIABEIRA PALUMA
}

\section{Gisely Correa de Moura ; Américo Wagner Júnior²; Juliano Zanella³ Sérgio Miguel Mazaro ${ }^{2}$; Geisiane Otalakoski ${ }^{4}$ Lucas Pedro de Lima ${ }^{5}$}

${ }^{1}$ Doutora Enga Agrônoma, Bolsista Pós-Doc Fundação Araucária - UTFPR - Câmpus Dois Vizinhos - PR, Brasil. E-mail: correa.gisely@gmail.com.

${ }^{2}$ Eng. Agr. DSc. Professor da UTFPR - Universidade Tecnológica Federal do Paraná

- Câmpus Dois Vizinhos - Dois Vizinhos, PR - CEP: 85660-000. E-mail:

${ }^{3}$ Químico, Doutorando em Ciência de Alimentos - UTFPR - Câmpus Dois Vizinhos PR, Brasil.

${ }^{4}$ Engenheira Florestal, autônoma, Dois Vizinhos - PR, Brasil.

${ }^{5}$ Tecnologo em horticultura, autônomo, Dois Vizinhos - PR, Brasil.

Recebido em: 16/11/2015 - Aprovado em: 10/12/2015 - Publicado em: 21/12/2015 DOI: http://dx.doi.org/10.18677/Agrarian_Academy_017

A goiabeira, fruteira nativa brasileira encontra-se disseminada em regiões de clima tropical e subtropical. A forma de propagação sexuada pode ser útil para obtenção de porta-enxertos e para os programas de melhoramento. Porém, as sementes desta fruteira perdem rapidamente a viabilidade quando armazenadas, necessitando-se de estudos que permitam mantê-las viáveis por maior período. 0 objetivo do trabalho foi avaliar o vigor e a qualidade fisiológica de sementes de goiabeira Paluma de acordo com o período de armazenamento, condição de conservação e uso de ácido giberélico. Foram conduzidos dois experimentos, sendo ambos realizados na UTFPR - Dois Vizinhos (PR). Para o experimento 1, as sementes foram separadas em 6 lotes, sendo cada um embebido em ácido giberélico durante 5 minutos, nas concentrações de 0,100, 200, 300, 400 e 500 mg $\mathrm{L}^{-1}$. Posteriormente, cada lote foi separado em três sublotes, sendo constituídas pelo ambiente natural durante 24 horas e, armazenamento em duas condições (ambiente natural e ambiente controlado sob temperatura de $5^{\circ} \mathrm{C}$ ) durante 20 dias. Para 0 experimento 2, as sementes foram divididas em dois lotes, sendo o primeiro armazenadas em temperatura ambiente e o segundo em temperatura controlada à $5^{\circ} \mathrm{C}$. Cada lote foi dividido em três sublotes de aco rdo com o tipo de embalagem utilizada, sendo estes de papel, plástico e a vácuo. As sementes embaladas foram armazenadas por sete períodos de armazenamento (0, 15, 30, 45, 60, 75 e 90 dias). As sementes de goiabeira Paluma mantiveram-se viáveis até 20 dias de armazenamento com condição natural ou de temperatura de $5^{\circ} \mathrm{C}$. Não é necessário o uso de giberelina para semente de goiabeira.

PALAVRAS-CHAVE: conservação, goiaba, Psidium guajava, propagação sexuada.

\section{TIME AND FORM OF SEED STORAGE ON GUAVA PALUMA}

\section{ABSTRACT}

The guava, Brazilian native fruit that is widespread in tropical and subtropical regions. The form of sexual propagation may be useful for obtaining rootstocks and 
for breeding programs. But the seeds of this plant quickly lose viability when stored, being necessary studies to keep them viable for long time. The objective was to evaluate the vigor and the physiological quality of "Paluma" guava seeds according to the storage, conservation conditions and use of gibberellic acid. Two experiments were conducted, in UTFPR - Dois Vizinhos (PR). For experiment 1, the seeds were divided into 6 lots, each soaked in gibberellic acid for 5 minutes at concentrations of $0,100,200,300,400$ and $500 \mathrm{mg} \mathrm{L}^{-1}$. Subsequently, each lot was divided into three lots and is constituted by the natural environment for 24 hours and storage at different conditions (natural environment and controlled environment at $5^{\circ} \mathrm{C}$ ) for 20 days. For the second experiment, the seeds were divided into two lots, the first being stored at room temperature and the second at controlled temperature of $5^{\circ} \mathrm{C}$. Each lot was divided into three lots according to the type of package used, which are paper, plastic and vacuum. Packaged seeds were stored for seven periods of storage $(0,15,30,45,60,75$ and 90 days). The "Paluma" guava seeds remained viable up to 20 days of storage with natural condition or $5^{\circ} \mathrm{C}$ temperature storage. Applies of Gibberellin is not necessary for guava seed.

KEYWORDS: guava, Psidium guajava, conservation, sexual propagation.

\section{INTRODUÇÃO}

A goiabeira, Psidium guajava L., é fruteira brasileira, pertencente a família Myrtaceae, cuja disseminação está em regiões de clima tropical e subtropical, o que a caracteriza ser planta rústica com possibilidade de adaptação em diferentes condições edafoclimáticas (CAVALCANTE et al., 2010). Os frutos ocupam lugar de destaque por sua excelente qualidade, apresentando elevado potencial industrial (FRANCISCO et al., 2005) e com satisfatório teor de vitamina C (POMMER \& MURAKAMI, 2009), podendo ser consumido in natura ou processado, nas formas de doces, geleias, compotas, sucos, dentre outras (SÃO JOSÉ et al., 2003).

Esta espécie frutífera pode ser propagada pelos métodos sexuado e/ou assexuado, sendo este último muito usado, principalmente por meio das técnicas como o enxertia e estaquia (COSTA, 2003), uma vez que permitem obter plantas uniformes geneticamente, além de reduzir o período juvenil.

Apesar disso, o emprego da via sexuada torna-se obrigatório nos programas de melhoramento genético para esta espécie e na produção de porta-enxertos destinados a enxertia, necessitando-se em alguns casos manter tais sementes armazenadas até o momento propício para o uso, para troca de materiais entre melhoristas, que buscam testar genótipos promissores em outros locais ou para o viveirista utilizá-la para comercialização ou para produção de mudas.

Além disso, a cultura da goiabeira vem evoluindo muito nos últimos anos, principalmente devido ao desenvolvimento de cultivares mais produtivas, com frutos de dupla finalidade (mesa e/ou indústria) (SOUZA et al., 2009). Isso foi consequência de seleção ocorrida em plantas originadas por sementes, no qual permitem obter genótipos com tais características visando dupla finalidade (FERNANDES-SANTOS et al., 2010). Com isso, torna-se necessário a realização de estudos sobre a qualidade fisiológica das sementes de goiabeira armazenadas por longos períodos e em diferentes condições de conservação, uma vez que CORREA et al. (1998) verificaram rápida perda de vigor destas quando armazenadas em embalagem permeável.

Como a qualidade fisiológica das sementes, quando armazenadas, está diretamente relacionada ao tipo de embalagem empregada, o uso das permeáveis pode nem sempre ser o mais adequado para goiabeira. Uma das embalagens que 
vem tendo destaque para as sementes é a vácuo, uma vez que, nestas condições reduz-se o teor de oxigênio, diminuindo-se o metabolismo das mesmas, sem reduzir o teor de umidade destas (CORLETT et al., 2007).

É possível que após o armazenamento das sementes haja atraso no início do processo germinativo ou que o mesmo seja desuniforme posterior a semeadura, devido a alteração que ocorre com o metabolismo. Assim, é necessária a aplicação de técnicas conjuntas que possibilitem evitar a desuniformidade e o atraso em tal processo como a aplicação de giberelina, já demonstrado por PRADO NETO et al., (2007), como vantagem para sementes de jenipapo (Genipa americana L.).

A giberelina é promotora da germinação, sendo hormônio que apresenta receptores nas células das sementes e desencadeia a expressão de genes relacionados com a síntese de hidrolises que irão agir na degradação das reservas do endosperma (TAIZ \& ZEIGER, 2013). Durante a germinação, as giberelinas induzem a síntese de enzimas hidrolíticas, degradando reservas nutritivas acumuladas no endosperma ou no embrião, à medida que a semente amadurece. Essa degradação de carboidratos e de proteínas proporciona energia para retomar o crescimento do embrião e da plântula (BORGHETTI, 2004; TAIZ \& ZEIGER, 2013).

Como para goiabeira os trabalhos são escassos e necessários, propôs no presente trabalho avaliar a qualidade fisiológica das sementes de acordo com 0 período de armazenamento, condição de conservação e uso de giberelina.

\section{MATERIAL E MÉTODOS}

Foram realizados dois experimentos, sendo ambos conduzidos no Laboratório de Fisiologia Vegetal e na Unidade de Ensino e Pesquisa Viveiro de Produção de Mudas, da Universidade Tecnológica Federal do Paraná - Câmpus Dois Vizinhos (PR).

Para implantação dos experimentos, utilizou-se sementes extraídas de frutos maturos de goiabeira Paluma provenientes do mercado local do município. Para a extração das sementes, dividiram-se os frutos pela metade e com auxílio de bisturi retirou-se cada semente, sendo a mucilagem manualmente retirada, por meio de fricção em peneira de malha fina. Posteriormente, as sementes foram lavadas em água corrente e dispostas em papel toalha, onde permaneceram durante 72 horas à sombra para retirada do excesso de umidade.

\section{Experimento 1:}

Após extração e secagem, as sementes foram dispostas em 6 lotes, sendo cada um embebido em solução com ácido giberélico durante 5 minutos, nas concentrações de 0, 100, 200, 300, 400 e $500 \mathrm{mg} \mathrm{L}^{-1}$. Para preparo das soluções de ácido giberélico utilizou-se 0 produto comercial ProGibb®, exceção para 0 tratamento com $0 \mathrm{mg} \mathrm{L} \mathrm{L}^{-1}$, no qual colocou-se somente água destilada. Posteriormente, cada lote foi separado em três sublotes, que variaram de acordo com sua condição, sendo mantida em ambiente natural durante 24 horas e em ambiente natural e ambiente controlado sob temperatura de $5^{\circ} \mathrm{C}$ durante 20 dias. As sementes nestas condições foram mantidas em embalagem de papel kraft. Após cada período, as sementes foram semeadas em canteiros de areia $(2 \mathrm{~m} \times 1,5 \mathrm{~m})$ contendo areia grossa como substrato. O delineamento experimental foi inteiramente casualizado, em esquema fatorial $3 \times 6$ (condição de armazenamento $x$ concentração de ácido giberélico), com quatro repetições, sendo a unidade experimental constituída por 50 sementes. Foram analisadas após 45 dias de semeadura a porcentagem de germinação e índice de velocidade de emergência 
das sementes (IVE) (décimo segundo ao trigésimo terceiro dia), sendo que os dados de ambas variáveis foram submetidos a análise de variância e ao teste de Tukey ( $p$ $\leq 0,05$ ). Anteriormente, os dados de IVE foram transformados em $\sqrt{x+1}$, por não terem apresentado normalidade segundo o teste de Lilliefors.

\section{Experimento 2:}

Decorrido o tempo de secagem das sementes a sombra (72 horas), as mesmas foram separadas em dois lotes, sendo no primeiro armazenadas em temperatura ambiente e no segundo em controlada à $5^{\circ} \mathrm{C}$. Cada lot $\mathrm{e}$ foi dividido em três sublotes de acordo com o tipo de embalagem utilizada, sendo estes de papel kraft dobrado na extremidade, plástico selado e vácuo. As sementes foram então armazenadas, cada qual em condição e embalagem, por sete períodos de armazenamento $(0,15$, $30,45,60,75$ e 90 dias). Após cada período de armazenamento, as sementes foram semeadas em canteiros $(2 \times 1,5 \mathrm{~m})$, com areia lavada, no interior de casa de sombreamento com redução de $50 \%$ de luminosidade. O delineamento foi inteiramente casualizado, em esquema fatorial $2 \times 3 \times 7$ (condição de armazenamento $\mathrm{x}$ embalagem $\mathrm{x}$ período de armazenamento), com quatro repetições, sendo a unidade experimental constituída por 50 sementes. Aos 45 dias da semeadura foi analisada a porcentagem de emergência e índice de velocidade de emergência (IVE) (décimo nono ao quadragésimo quinto dia), sendo a germinação e IVE transformados $\sqrt{x+1}$, de acordo com a necessidade demonstrada pelo teste de Lilierfors.

A significância dos efeitos dos tratamentos foi determinada por meio do Teste F. Para os fatores qualitativos, as médias foram comparadas por meio do Teste de Tukey, e para o fator quantitativo foram ajustadas regressões polinomiais.

\section{RESULTADOS E DISCUSSÃO}

\section{Experimento 1:}

As sementes da goiabeira Paluma iniciaram a emergência aos 12 dias após semeadura, nos tratamentos em que as mesmas foram mantidas em ambiente natural durante 24 horas, independente da concentração de ácido giberélico utilizado. Isso pode ser explicado pela qualidade inicial da semente, sugerindo-se que até o momento não houve perda de água considerável e nem oxidação, ou seja, não houve alteração das substâncias presentes nas mesmas, não sendo necessário o uso de hormônios promotores para auxiliar na germinação.

De acordo com os resultados não houve interação significativa a 5\% de probabilidade entre a condição de armazenamento $x$ concentração de ácido giberélico e para o fator concentração de ácido giberélico sobre as variáveis analisadas. Entretanto, o fator condição de armazenamento foi significativo para as variáveis germinação e IVE (Tabela 1), tendo as maiores médias, com $81,83 \%$ e 2,14 , com as sementes mantidas 24 horas em ambiente natural respectivamente. 
TABELA 1: Percentual de germinação e índice de velocidade de emergência (IVE) de sementes de goiabeira de acordo com a condição de armazenamento.

\begin{tabular}{lcc}
\hline Condição de armazenamento & Germinação (\%) & IVE \\
\hline Ambiente natural 24 horas & $81,33 \mathrm{a}$ & $2,14 \mathrm{a}$ \\
Ambiente natural 20 dias & $70,83 \mathrm{~b}$ & $1,38 \mathrm{~b}$ \\
Ambiente controlado $\left(5^{\circ} \mathrm{C}\right)$ 20 dias & $57,42 \mathrm{c}$ & $1,34 \mathrm{~b}$ \\
\hline CV $(\%)$ & 21,20 & 9,78 \\
\hline
\end{tabular}

${ }^{*}$ Médias seguidas pela mesma letra minúsculas na coluna não diferem entre si pelo teste de Tukey a $5 \%$ de probabilidade.

De acordo com a Tabela 1, quando as sementes foram mantidas em condição natural por 20 dias, as médias de germinação foram inferiores aquelas em que permaneceram na mesma condição por 24 horas, o que pode ser em decorrência do consumo de reservas das mesmas durante o período, afetando significativamente a capacidade de germinação e o vigor das sementes.

Entretanto, na condição de armazenamento de $5^{\circ} \mathrm{C}$ por 20 dias, as sementes apresentaram a menor média de germinação, o que pode ser causado por algum dano nas mesmas pelo frio durante o armazenamento, uma vez que trata-se de espécie tropical. Outra hipótese pode estar relacionada há alguma desordem no processo metabólico das sementes, fazendo com que não ocorresse especificadamente o dano e sim o atraso para retomada do crescimento do embrião e consequente germinação.

De acordo com SABEHAT et al., (1996), tanto culturas de origem temperada ou tropical sofrem injúrias quando expostas a baixas temperaturas. Injúria por frio é desordem fisiológica que se desenvolve em algumas plantas tropicais e subtropicais quando expostas à temperatura abaixo de 10 a $12^{\circ} \mathrm{C}$. RAB \& SALVEIT, (1996), afirmam que injúria por temperatura baixa pode causar redução na germinação $\mathrm{e}$ crescimento, diminuindo a viabilidade da semente. As baixas temperaturas atuam na estabilidade e na atividade enzimática, favorecendo o metabolismo de carboidratos, supostamente envolvidos na manutenção da integridade das membranas celulares (PETERBAUER \& RICHTER 2001). Contundo, supõe-se que isso tenha também ocorrido para goiabeira, mas estavam apenas iniciando, pois foi possível obter germinação próxima a 57\%.

\section{Experimento 2:}

De acordo com os resultados obtidos pela análise de variância para germinação e IVE não foi obtido efeito significativo para as interações condição de armazenamento $\mathrm{x}$ embalagem $\mathrm{x}$ período de armazenamento, condição de armazenamento $\mathrm{x}$ embalagem, condição de armazenamento $\mathrm{x}$ período de armazenamento e embalagem $x$ período de armazenamento, bem como, para o fator embalagem. Entretanto, para os fatores condição de armazenamento e período de armazenamento houve efeito significativo para germinação (Tabela 2 e Figura 1, respectivamente).

Observou-se na Tabela 2 que as sementes de goiabeira Paluma quando mantidas em temperatura a 5 o C constante apresentaram maior germinação em relação à condição natural. Isso pode ter ocorrido pelo fato de que a redução da temperatura pode ter promovido diminuição da atividade metabólica, o que 
proporcionou menor gasto de energia nas sementes armazenadas, reduzindo 0 consumo de reservas, possibilitando maior germinação.

PONTES et al., (2006) afirmam que sementes de Caesalpinia peltophoroides armazenadas a $5^{\circ} \mathrm{C}$ mantiveram a porcentagem de germ inação constante até 220 dias, enquanto a $20{ }^{\circ} \mathrm{C}$ a redução foi detectada a partir dos 120 dias de armazenamento. Da mesma forma ALVES et al., (2006) concluíram que a baixa temperatura de armazenamento das sementes influencia positivamente na porcentagem de germinação das sementes de maracujá doce.

TABELA 2: Germinação de sementes de goiabeira Paluma de acordo com a condição de armazenamento.

\begin{tabular}{lc}
\hline Condição de armazenamento & Germinação \\
\hline $5^{\circ} \mathrm{C}$ & $23,16 \mathrm{a}$ \\
Ambiente & $18,68 \mathrm{~b}$ \\
\hline C.V. (\%) & 25,02 \\
\hline${ }^{*}$ Médias seguidas pela mesma letra minúsculas não diferem entre si pelo teste de Tukey a $5 \%$ de \\
probabilidade.
\end{tabular}

Quanto aos períodos de armazenamento, o mesmo mostrou comportamento quadrático decrescente com coeficiente de determinação $\left(r^{2}=0,89\right)$.

Pela Figura 1 observou-se que as sementes de goiabeira Paluma foram perdendo a capacidade germinativa com o passar do tempo, mantendo-se a média de emergência entre $90 \%$ nos primeiros 15 dias. Resultados semelhantes foram obtidos por PEREIRA \& ANDRADE (1994) e CORREA et al. (1998). Verificou-se que as sementes de goiabeira Paluma não apresentam mais germinação após 60 dias de armazenamento. Isso reforça a hipótese levantada no experimento 1, em que o frio pode causar danos às sementes de goiaba, quando expostos por período prolongado, mantendo até os 20 dias, germinação acima de $50 \%$.

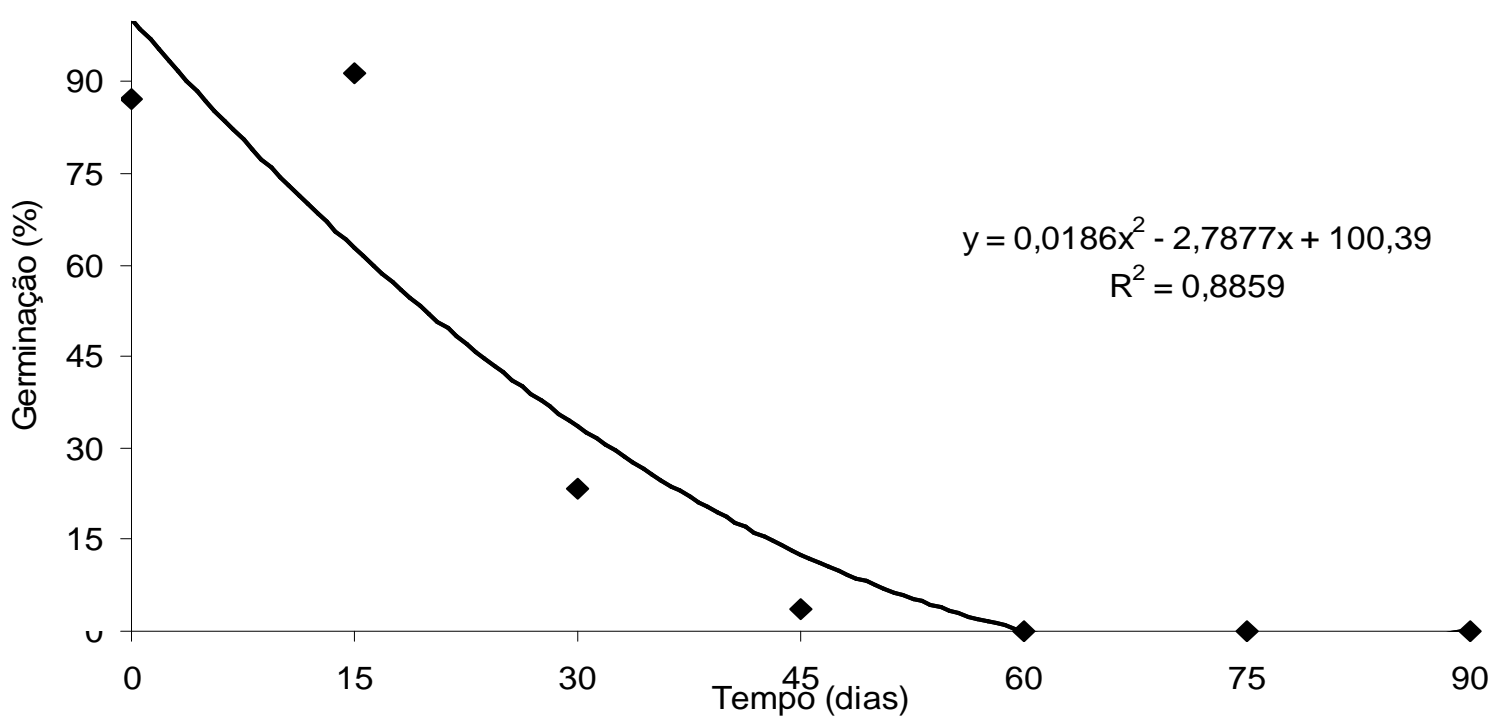

FIGURA 1: Germinação de sementes de goiabeira de acordo com o período de armazenamento. 
Em relação aos resultados obtidos para IVE, somente obteve-se significância para o fator período de armazenamento (Figura 2). Os demais fatores, bem como, todas interações dos fatores não foram estatisticamente significativas.

Segundo a Figura 2, o maior IVE foi obtido quando as sementes foram imediatamente semeadas em substrato, uma vez que houve redução linear decrescente com o prolongamento do tempo de armazenamento. Supõe-se que estas respostas possam estar ligadas a menor disponibilidade de recursos nas sementes de goiaba Paluma ao longo do período de armazenagem, fazendo com isso redução no vigor e possibilitando menor emergência.

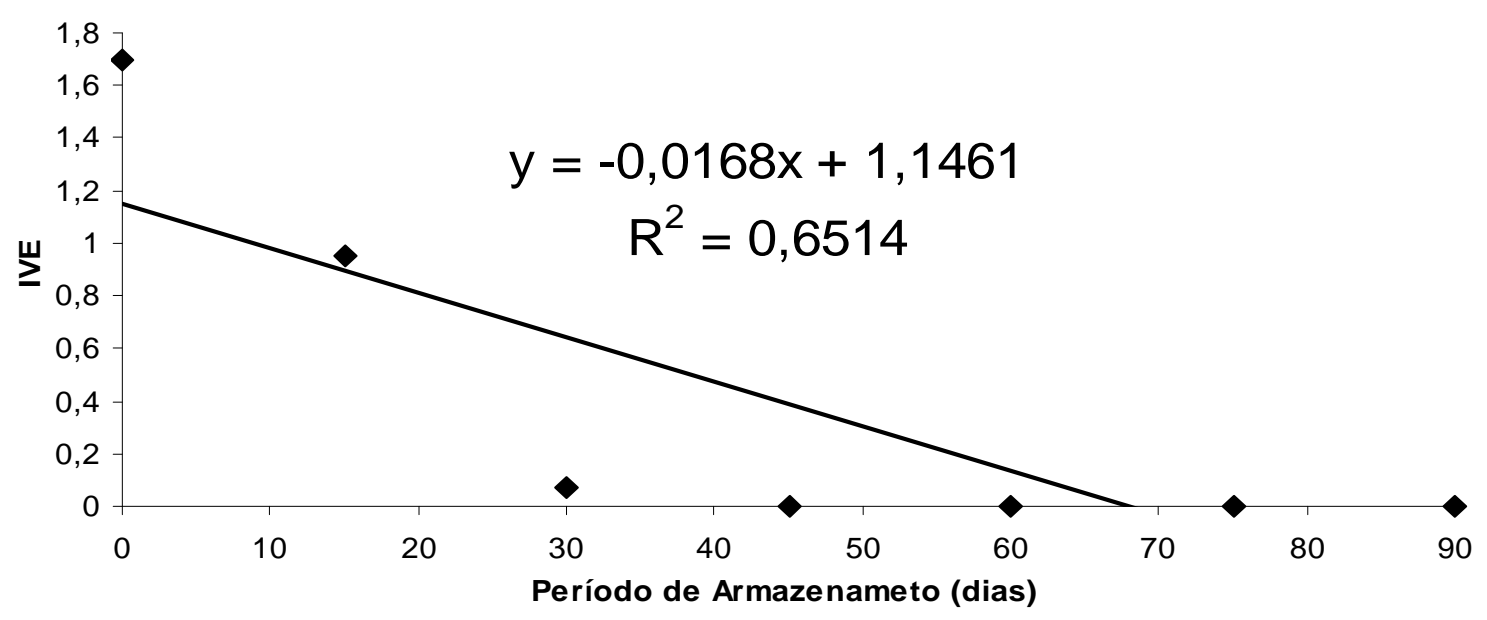

FIGURA 2: Índice de velocidade de emergência (IVE) de sementes de goiabeira de acordo com o período de armazenamento.

\section{CONCLUSÃO}

As sementes de goiabeira Paluma preservam o poder germinativo se mantidas em ambiente natural ou de temperatura controlada $\left(5^{\circ} \mathrm{C}\right)$, por no máximo 20 dias, independente da embalagem utilizada. $O$ uso de ácido giberélico não se faz necessário para sementes desta fruteira.

\section{REFERÊNCIAS}

ALVES, C. Z.; SÁ, M. E.; CORRÊA, L. S.; BINOTTI. F. F. S. Efeito da temperatura de armazenamento e de fitoreguladores na germinação de sementes de maracujá doce e desenvolvimento inicial de mudas. Acta Scientiarum. Agronomy, v. 28, n. 3, p. 441-448, 2006. Disponível em: <http://dx.doi.org/10.4025/actasciagron.v28i3.972>. doi: $10.4025 /$ actasciagron.v28i3.972

BORGHETTI, F. Dormência embrionária. In: FERREIRA, A. G.; BORGHETTI, F. (Org.). Germinação: do básico ao aplicado. Porto Alegre: Artimed, 2004, p.109-123

CAVALCANTE, L. F.; VIEIRA, M. S.; SANTOS, A. F.; OLIVEIRA, W. M.; NASCIMENTO, J. A. M. Água salina e esterco bovino líquido na formação de mudas de goiabeira cultivar Paluma. Revista Brasileira de Fruticultura, Jaboticabal. v.32, n.1, p.251-261, 2010. Disponível em: <http://dx.doi.org/10.1590/S010029452010005000037>. doi: 10.1590/S0100-29452010005000037 
CORLETT, F. M. F.; BARROS, A. C. S.A.; VILLELA, F. A. Qualidade fisiológica de sementes de urucum armazenadas em diferentes ambientes e embalagens. Revista Brasileira de Sementes. V.29, n. 2, p.148-158, 2007. Disponível em: < http://dx.doi.org/10.1590/S0101-31222007000200021>. doi: 10.1590/S010131222007000200021

CORREA, F. L. O.; CHALFUN, N. N. J.; NORBERTO, P. M.; HOFFMAN, A. Efeito da embalagem e do ambiente de armazenamento na germinação e vigor de sementes de goiabeira (Psidium guajava L.). In: Congresso Brasileiro de Fruticultura, 15, Poços de Caldas, 18/23 out. 1998. Anais. Lavras: UFLA, 1998. p.369.

COSTA, A. F. S.; COSTA, A. N. Tecnologia para Produção de Goiaba. Vitoria: Incaper, 2003. 341p.

FERNANDES-SANTOS, C. A., CUNHA-CASTRO, J. M., FRANCA-SOUZA, F., ALCANTARA-VILARINHO, A., FERREIRA, F. R., GOMES-PADUA, J., ESTIGARRIBIA-BORGES, R. M., BARBIERI, R. L., CLARET DE SOUZA, A. D. G., AMORIM-RODRIGURES, M., Prospecting and morphological characterization of Brazillian Psidium germplasm. Acta Horticulturae. 849, 63-68, 2010. Disponível em: <http://dx.doi.org/10.17660/ActaHortic.2010.849.6>. doi: 10.17660/ActaHortic.2010.849.6

FRANCISCO, V. L. F. DOS S., BAPTISTELLA, C. S. L., AMARO, A. A. A cultura da goiaba em São Paulo, 2005.

PEREIRA, T. S.; ANDRADE, A. C. S. Germinação de Psidium guajava L. e Passiflora edulis Sims - Efeito da temperatura, substrato e morfologia do desenvolvimento pós-seminal. Revista Brasileira de Sementes, Brasília. V.16, n.1, p.58-62, 1994. Disponível em: <http://dx.doi.org/10.17801/0101-3122/rbs.v16n1p5862 >. doi: 10.17801/0101-3122/rbs.v16n1p58-62

PETERBAUER, T.; RICHTER, A. Biochemistry and physiology of raffinose family oligosaccharides and galactosyl cyclitols in seeds. Seed Science Research, v. 11, p. 185-197, 2001. Disponível em: < http://dx.doi.org/10.1079/SSR200175>. doi: 10.1079/SSR200175

POMMER, C. V.; MURAKAMI, K. R. N. Breeding Guava (Psidium guajavaL.). In: JAIN SM, PRIYADARHAM PM (eds). Breeding plantation tree crops: tropical species. p. 83-120, 2009.

PONTES, C. A.; CORTE, V. B.; BORGES, E. E. L.; SILVA, A. G.; BORGES, R. C. G. Influência da temperatura de armazenamento na qualidade das sementes de Caesalpinia peltophoroides Benth. (SIBIPIRUNA). Revista Árvore, Viçosa-MG, v.30, n.1, p.43-48, 2006. Disponível em: <http://dx.doi.org/10.1590/S010067622006000100006>. doi: 10.1590/S0100-67622006000100006

PRADO NETO, M.; Dantas, A. C. V. L.; Vieira, E. L.; Almeida, V. O. Germinação de sementes de jenipapeiro submetidas à pré-embebição em regulador e estimulante 
vegetal. Ciência agrotécnica, v. 31, n. 3, p. 693-698, 2007. Disponível em: <http://dx.doi.org/10.1590/S1413-70542007000300014> doi: $10.1590 / \mathrm{S} 1413-70542007000300014$

RAB, A.; SALTVEIT, M. E. Sensitivity of seedling radicles to chilling and heat-shockinduced chilling tolerance. Journal of American Society for Horticultural Science, v.121, n.4, p. 711-715, 1996.

SABEHAT, A., WEISS, D.; LURIE, S. The correlation between heat-shock protein accumulation and persistence and chilling tolerance in tomato fruit. Plant Physiology, v.110, n. 2, p.531-537, 1996. Disponível em: <http://dx.doi.org/10.1104/ pp.110.2.531>. doi: 10.1104/pp.110.2.531

SÃO JOSÉ, A. R.; REBOUÇAS, T. N. H.; DIAS, N. O.; HOJO, R. H.; BOMFIM, M. P. Cultivo de goiabeira no Brasil. In: Primeiro simpósio internacional de la guayaba, 1., Aguascalientes. Memória Aguascalientes: México, 2003. 84-115p. 2003.

SOUZA, M. G.; FREITAS, V. M.; MATOS, J. K. A.; SILVA, J. G. P.; RESENDE, F. O.; TEXEIRA, R. R.; CARNEIRO, R. M. D. G. (2009) Reaction of Psidium spp. to Meloidogyne enterolobii and their grafting compatibility with P. 48 guajava $\mathrm{cv}$ Paluma. Resumos do II International Congress of Tropical Nematology, Maceió (Brazil) October 4-9 th, Abstract 69.

TAIZ, L.; ZEIGER, E. Fisiologia Vegetal. 5. ed. São Paulo: Artmed, 2013.918p. 